\title{
Simbolizações de professores acerca da formação técnica integrada ao Ensino Médio
}

\author{
Adriana Cristina Ruescas Santana \\ Centro Estadual de Educação Tecnológica Paula Souza - CEETEPS, Brasil \\ Escola Técnica Estadual Tereza Ap ${ }^{a}$ Cardoso Nunes de Oliveira
}

Adelina de Oliveira Novaes

Universidade Cidade de São Paulo - UNICID, Brasil;

Fundação Carlos Chagas

\begin{abstract}
RESUMO
Por meio da abordagem psicossocial da Teoria das Representações Sociais, o estudo aqui relatado buscou compreender as simbolizações circulantes entre professores que vivenciaram o processo de implantação do Decreto $\mathrm{n}^{\circ}$ 5.154/04 e da Lei 11.741/08, em uma Escola Técnica Estadual do Centro de Educação Estadual Tecnológica Paula Souza, localizada na Zona Leste da cidade de São Paulo. Os e-mails trocados entre oito professores que trabalham com o Ensino Técnico Integrado ao Ensino Médio (ETIM) em diferentes escolas técnicas estaduais na cidade de São Paulo acerca do ensino médio integrado, associados aos planos de trabalho de professores da referida escola técnica estadual do Centro Paula Souza e um documento produzido de forma colegiada sobre o ETIM pelo Sindicato dos Trabalhadores do Centro Paula Souza compõem o corpus de informações, que foi estudado respeitando-se os procedimentos da análise de conteúdo. Por meio da triangulação das fontes, foram analisadas as categorias temáticas encontradas, com vistas a propiciar a confrontação entre os três diferentes tipos de discursos elaborados pelos docentes. A pesquisa evidenciou um espectro de simbolizações destoantes, o que permitiu depreender a impossibilidade de delimitar uma representação acerca do Ensino Técnico Integrado ao Ensino Médio, vez que esse não consiste um objeto de representação para os docentes. Com base nas informações analisadas, pode-se afirmar que contribui para tal indefinição do objeto, a ausência de uma política pública de qualificação para os professores, bem como a falta de uma proposta institucional de formação integral para os alunos.
\end{abstract}

PALAVRAS-CHAVE: Ensino médio integrado. ETIM. Representações Sociais.

\section{SYMBOLIZATION OF TEACHERS ABOUT INTEGRATED TECHNICAL TRAINING TO HIGH SCHOOL}

\begin{abstract}
Through the psychosocial approach of the social representations theory, this study sought for understand the symbolization of teachers who experienced the implementation process of the Brazilian Decree 5.154/04 and the Brazilian Law 11.741/08. The research was developed in a technical school, Escola Técnica Estadual do Centro de Educação Estadual Tecnológica Paula Souza, located at the east side of the São Paulo city. The e-mails exchanged among eight teachers who work with the technical education integrated to high school on this matter, the teachers work plans, and a document produced by The Work's Union of Centro Paula Souza
\end{abstract}


composed the corpus of information studied through de procedures of content analysis. The triangulation of the analysed information provided the confrontations of teachers' discourses. The analyses showed the impossibility to identify a social representation on the integrated technical education to high school, once this is not a representation object to the teachers. The absence of a public policy of teachers qualification contributes to this lack of definition of the social representation object, as well as the lack of an institutional propose of students integral development.

KEYWORDS: Integrated high school. ETIM. Social representations.

\section{SIMBOLIZACIONES DE PROFESORES ACERCA DE LA FORMACIÓN TÉCNICA INTEGRADO DE LA ENSEÑANZA MEDIA}

\section{RESÚMEN}

A través del enfoque psicossocial de la teoría de las respresentaciones sociales, el estudio aquí relatado ha buscado comprender las simbolizaciones circulantes entre profesores que han experimentado el proceso de implantación del Decreto $n^{\circ}$ 5.154/04 y de la ley 11.741/08, en una Escuela Técnica Estadual del Centro de Educación Tecnológica Paula Souza, localizada en la Zona Este de la Ciudad de São Paulo. Los intercambios de e-mails entre ocho profesores que trabajan con la Enseñanza Técnica Integrada a la Enseñanza Media, en diferentes escuelas técnicas estaduais en la Ciudad de São Paulo acerca de la enseñanza media integrada asociados a los planos de trabajo de profesores de la dicha escuela técnica estadual del Centro Paula Souza y uno documento producido de forma colegiada sobre el ETIM por el Sindicato de los Trabajadores del Centro Paula Souza componen el corpus de informaciones, que fue estudiado respetandose los procedimientos de análisis de contenido. A través de la triangulación de fuentes, fueron analisadas las categorias temáticas encontradas, con vistas a propiciar la confrontación entre los tres diferentes tipos de discursos elaborados pelos docentes. La investigación un espectro de simbolizaciones disonantes, lo que ha permitido inferir la imposibilidad de delimitar una representación acerda de la Enseñanza Técnica Integrada a la Enseñanza Media, porque ello no consiste un objeto de representación para los docentes. Con base en las informaciones analisadas, se puede afirmar que contribuye para tal indefinición del objeto la ausencia de una política pública de cualificación para los profesores, así como la falta de una propuesta institucional de formación integral para los estudiantes.

PALABRAS-CLAVE: Enseñanza Media Integrada. ETIM. Representaciones sociais.

\section{INTRODUÇÃO}

Compreender as simbolizações de professores pode favorecer o desenvolvimento de processos e de políticas que contribuam para a melhoria do Ensino Técnico Integrado ao Ensino Médio $^{1}$ (ETIM). Para tal, a pesquisa aqui relatada buscou, por meio da abordagem psicossocial

\footnotetext{
${ }^{1}$ O Decreto $\mathrm{n}^{\mathrm{o}} 5.154 / 04$, de 23 de julho de 2004, regulamenta o $§ 2^{\text {o }}$ do art. 36 e os arts. 39 a 41 da Lei no 9.394 , de 20 de dezembro de 1996 (Lei das Diretrizes e Bases da Educação Nacional - LDB) e determina que uma das formas de oferta de ensino técnico deve estar integrada ao ensino médio. De acordo com o Decreto, o aluno, nessa modalidade, deve cursar os componentes curriculares da Base Nacional Comum e os componentes da Educação Profissional de forma integrada.
} 
da Teoria das Representações Sociais, entender as simbolizações que circulam entre professores do ensino médio e do ensino profissionalizante sobre o ensino médio integrado.

As páginas que seguem buscam oferecer uma breve revisão de conceitos da Teoria das Representações Sociais que serviram como instrumental para a análise das informações coletadas. Com vistas a obter elementos acerca do objeto da representação estudado, na sequência, foi apresentado um sintético panorama da história da educação profissional no estado de São Paulo, seguido da estratégia metodológica e das análises desenvolvidas a partir da triangulação das categorias temáticas encontradas pela sistematização dos conteúdos das trocas de $e$-mails entre professores, associada aos planos de trabalho docentes e de documento produzido de forma colegiada pelo Sindicato dos Trabalhadores do Centro Paula Souza (SINTEPS).

\section{O INSTRUMENTAL TEÓRICO DAS REPRESENTAÇÕES SOCIAIS COMO ESTRATÉGIA DE ACESSO ÀS SIMBOLIZAÇÕES DOCENTES}

O exercício da docência em sala de aula, bem como em outros espaços escolares, é essencialmente relacional, o que caracteriza os professores como intérpretes de conteúdos simbólicos e mediadores de conhecimentos para os estudantes. Significa dizer que a profissão docente tem uma particularidade que é a de construir simbolizações do que e de como ensinar, o que ocorre antes mesmo do exercício da profissão.

O conhecimento adquirido durante o período de formação, a convivência com outros professores e a mudança de papel de educando para educador promovem a constante renovação das simbolizações acerca do exercício profissional. Tais simbolizações constroem saberes que, apesar de estarem em contínua transformação, constituem-se a partir de uma tradição, por meio do processo de interação social (SEIDMANN et. al., 2012).

Ocorre, no entanto, que a coleção de normas que regula a formação e o trabalho docente promove um investimento intenso de adaptação, não apenas por parte do profissional em formação, mas também do profissional em exercício. Tal exigência acaba por direcionar a energia de trabalho dos professores no sentido da conformação às normas e pouco espaço resta à produção e à sistematização de novos saberes obtidos pela experiência docente (TARDIF, 2012).

É por entender que as mudanças nas recomendações para o ensino médio profissional devem motivar um verdadeiro câmbio das propostas curriculares e metodológicas no contexto das escolas que a investigação realizada considerou que o "ensino médio integrado" poderia se 
constituir em um objeto de representação para o grupo de docentes afetados pela política. Nesse sentido, a compreensão do que os docentes entendem por "ensino médio integrado" pode favorecer a concretização da política, bem como contribuir para o incremento da qualidade da educação nesse âmbito de ensino.

Grosso modo, a Teoria das Representações Sociais (TRS), inaugurada por Moscovici (1961, 1978, 2012), trata da elaboração simbólica dos objetos por grupos sociais. Para o autor da Teoria, "as representações sociais são entidades quase tangíveis; circulam, cruzam-se e cristalizam-se continuamente por meio da fala, do gesto, do encontro no universo cotidiano" (MOSCOVICI, 2012, p.39).

Nesse tocante, de acordo com Novaes; Sousa (2013), a inovação da Teoria proposta por Moscovici reside na forma como o autor apresenta o entrosamento entre o coletivo e o individual, que se manifesta pelas comunicações interpessoais e intergrupais, surgidas a partir da necessidade do sujeito em harmonizar suas falas e atitudes por meio das representações sociais. Por ser fruto de um pensamento negociado entre pares, a fluidez das representações sociais, no entanto, é modificada pela criatividade do sujeito e por sua possibilidade de mudança na vida social, o que permite a existência de diferentes representações sociais dentro do próprio grupo $^{2}$.

Arruda (2002) explica que a referida Teoria parte da premissa que existem distintas formas de conhecer e de se comunicar, guiadas por objetivos diferentes, que são móveis e que produzem impressões na sociedade. Desse modo, a busca pelo conhecimento dá-se por meio de uma construção e faz-se necessário descolar as estruturas do saber considerando a subjetividade, o ambiente em que o sujeito está inserido e sua cultura.

Por sua vez, Jovchelovitch (2011) indica alguns caminhos para entender tal processo de construção e afirma que a Teoria da Representações Sociais tem como interesse compreender como os saberes são produzidos na e pela vida cotidiana: “A representação é um processo fundamental da vida humana; ele subjaz o desenvolvimento da mente, do $\mathrm{Eu}$, da sociedade e da cultura" (JOVCHELOVITCH, 2011, p.33). Em consonância, de acordo com Sá, “Os fenômenos de representação social estão espalhados por aí” (1988, p.21), na cultura, nas instituições, nas práticas sociais, nas comunicações interpessoais e de massa e nos pensamentos individuais. O fenômeno representacional, portanto, é o que movimenta um acontecimento,

\footnotetext{
${ }^{2}$ Residem, neste ponto, as principais diferenças entre o pensamento de Durkheim e Moscovici: enquanto Durkheim queria simplesmente dizer que a vida social é a condição de todo pensamento organizado e também a recíproca, sua atitude não provoca objeções, Moscovici considera a sociedade em processo constante de mudança. (MOSCOVICI, 2012, p. 39).
} 
uma informação, ou seja, é a vida que se dá aos fatos e o que origina um fenômeno é o seu objeto.

Ao considerar que as representações sociais são construídas por meio das relações da comunicação, pode-se afirmar que os fenômenos representacionais são frutos de discussões, causam tensões e provocam ações (GUARESCHI; ROSO, 2014, p.28). São comuns, na comunidade escolar, os confrontos de ideias e ideais entre os grupos e cada grupo geralmente representa o objeto que lhe afeta. Nesse sentido, "Reproduzir o discurso oficial pode ser necessário à sobrevivência, mas não é necessariamente uma prática cotidiana. Paralelamente ao discurso oficial, correm versões oficiosas, constituídas nas vivências, utilizadas ante as imposições mortíferas das ideologias dominantes” (ALMEIDA, 2005, p. 29).

Em outros termos, a negociação de sentidos entre os docentes comumente ocorre fora das reuniões formais. A sala dos professores, os corredores e demais espaços de circulação da escola, bem como os meios de comunicação eletrônicos, constituem os ambientes privilegiados de articulação de ideias e produção de representações sociais. No entanto, tais negociações são estimuladas pelas políticas e ancoradas em tradições, motivo pelo qual, na seção que se segue, serão resgatados aspectos associados à educação profissional no contexto paulistano.

\section{EDUCAÇÃo PROFISSIONAL, ENSINO TÉCNICO E ENSINO MÉDIO INTEGRADO}

No caso específico do estado de São Paulo, segundo Cunha (2005), em 1892, o Governo fez aprovar uma lei de reforma do ensino público, motivado pela necessidade de dar educação aos menores de 16 anos no período noturno, uma vez que muitos deles trabalhavam e não poderiam frequentar escola no período diurno.

Duas décadas depois, em 1910, nasceu a rede estadual de educação profissional, por meio das leis 1.214 e 1.245, e, em 1935, a rede estadual paulista contava com 12 (doze) escolas. Em 1937, por meio da Lei ${ }^{\circ}$ 378, a Escola Normal de Artes e Ofícios Wenceslau Braz e as escolas de aprendizes artífices, mantidas pela União, transformaram-se em liceus, destinados ao ensino profissional "de todos os ramos e gráos".

Posteriormente, no ano de 1942, no Estado Novo, o ensino profissional teve prioridade no sentido de formar mão de obra. No mesmo período foi criado o Serviço Nacional de Aprendizagem Industrial (Senai) e o Comercial (Senac). Ainda em 1942, as escolas de aprendizes e ofícios foram transformadas em Escolas Técnicas Federais. Alinhada a isso, a trajetória da educação profissional foi redefinida por meio da Reforma de Capanema, quando 
foram criados Decretos Leis para o ensino secundário (Decreto Lei $n^{\circ}$ 4.244/1943); para o comercial (Decreto Lei ${ }^{\circ}$ 6141/1943); para o primário (Decreto Lei n ${ }^{\circ}$ 8.529/1946); para o normal (Decreto Lei $\mathrm{n}^{\circ}$ 8.530/1946) e para o agrícola (Decreto Lei $\mathrm{n}^{\circ}$ 9.613/1946).

Separados por dois Ministérios, o ensino secundário e o normal estavam sob a competência do Ministério da Justiça e Negócios Interiores. Tinham por objetivo formar as elites condutoras do País e o ensino profissional era da competência do Ministério da Agricultura, Indústria e Comércio. Era destinado a formar os menos afortunados e aumentar a força de trabalho. Até, então "O ensino secundário e o normal, de um lado, e o ensino profissional, de outro, não se comunicavam nem propiciavam circulação de estudos" (REGATTIERE; CASTRO, 2010, p.18).

Em 1961, a primeira Lei de Diretrizes e Bases da Educação, a Lei nº 4.024 (BRASIL, 1961), destacou-se por ter equiparado o ensino profissional, do ponto de vista de equivalência, ao ensino acadêmico. Em São Paulo, o Centro Estadual de Educação Tecnológica Paula Souza (CEETEPS), contexto de coleta de informações do presente estudo, foi criado em 1969 pelo governador Roberto Costa de Abreu Sodré, como uma entidade autárquica, não ligada à Secretaria do Estado de Educação ${ }^{3}$. O CEETEPS iniciou suas atividades em 1970, com a instalação de dois cursos superiores, um na cidade de São Paulo e outro na cidade de Sorocaba. No entanto, foi apenas em 1981 que o CEETEPS passou a atuar na área de formação profissional de nível técnico, ao assumir as 12 escolas técnicas industriais. Em 1994, a partir do Decreto 37.735 de 27 de outubro de 1993, foram incorporadas outras 84 unidades de escolas técnicas estaduais ao CEETEPS.

Atualmente, conforme informações institucionais do Centro Paula Souza, a instituição administra 218 Escolas técnicas estaduais (Etecs), voltadas para formação de nível médio e 65 Faculdades de tecnologia (Fatecs), voltadas para formação de nível superior. As Etecs atendem a 212 mil estudantes nos ensinos técnico, médio e técnico integrado ao médio, com 135 cursos técnicos para os setores industrial, agropecuário e de serviços. Inclui habilitações na modalidade semipresencial, Educação de Jovens e Adultos (EJA) e especialização técnica. As Fatecs possuem mais de 73 mil alunos matriculados em 72 cursos de graduação tecnológica em diversas áreas, como Construção Civil, Mecânica, Informática, Tecnologia da Informação, Turismo, entre outras. Nelas, além da graduação, são oferecidos cursos de pós-graduação, atualização tecnológica e extensão.

\footnotetext{
${ }^{3}$ Hoje ligada à Secretaria de Desenvolvimento Econômico, Ciência, Tecnologia e Inovação.
} 
No estado de São Paulo, o Centro Paula Souza e o Instituto Federal somam 236 mil alunos matriculados na Educação Profissional de Nível Médio ${ }^{4}$. No entanto, a grande expansão na oferta ocorreu apenas nos últimos anos. Apesar de não possuir grande prestígio, a educação profissional ocupa um grande espaço no sistema educacional brasileiro. Há mais de cem anos, procura-se regulamentar essa modalidade de educação que se constitui para atender à classe trabalhadora. Nesse sentido, em julho de 2004, foi aprovado o Decreto $\mathrm{n}^{\circ}$ 5.154/04, com uma proposta de educação integral.

Embora a formação profissional, historicamente, tenha se destinado a preparar mão de obra para atendimento ao mercado de trabalho ${ }^{5}$, a aprovação do referido Decreto pode ser compreendida como uma conquista da classe trabalhadora, tendo em vista o retorno dos investimentos para ampliação da Rede Federal de Ensino, que havia sido paralisada durante a vigência do Decreto n ${ }^{\circ} 2.208 / 97^{6}$.

A instituição do Decreto $\mathrm{n}^{\circ}$ 5.154/04, tendo em vista o anseio da comunidade acadêmica por grandes transformações em relação à mudança de concepções da educação profissional, foi um tanto criticada por ter sido utilizado novamente um decreto para a regulamentação da integração, o que manteve as demais formas de oferta de ensino normatizadas pelo Decreto $\mathrm{n}^{\circ}$ $2.208 / 08$.

No entanto, os principais mentores do Decreto $n^{\circ}$ 5.154/04, Gaudêncio Frigotto, Marise Ramos e Maria Ciavatta, concluíram que, ainda assim, foi uma conquista, uma vez que se trata de uma proposta que visa a formação integral do Homem, que encaminha para uma formação omnilateral: "centrada no trabalho, na ciência, na tecnologia e na cultura" (FRIGOTTO, CIAVATTA, RAMOS, 2012 p.35).

A proposta de integração do Decreto 5.154/04 foi conectada ao texto da Lei 11.741/08, a qual alterou a os artigos 37, 39, 41 da LDB vigente, em especial no que tange à Educação de Jovens e Adultos, ao indicar que essa deveria ser articulada à educação profissional. As Diretrizes Curriculares Nacionais para o Ensino Médio atuais complementam as Diretrizes Curriculares Nacionais da Educação Básica (DCNEB) aprovadas pelo Conselho Nacional de Educação em 07 de abril de 2010 e estão de acordo com o Conselho Nacional de Educação

\footnotetext{
${ }^{4}$ Vale alertar que esta pesquisa não contempla as vagas do ensino profissional do Sistema $\mathrm{S}$, as vagas oferecidas pelo Programa Nacional de Acesso ao Ensino Técnico (PRONATEC), as vagas oferecidas por ONGs, igrejas e rede particular de ensino.

${ }^{5}$ Vale citar um dos ícones dos estudos do trabalho. Para Marx e Engels, (2011, p.30) “A força de trabalho em ação, o trabalho mesmo, é, portanto, a atividade vital peculiar ao operário, seu modo peculiar de manifestar a vida".

${ }^{6}$ O Decreto $\mathrm{n}^{\mathrm{o}}$ 2.208/97, revogado pelo Decreto 5.154/04, foi criticado pela comunidade acadêmica e pela sociedade desde a sua regulamentação em 17 de abril de 1997. Pereira e Teixeira expressam tal crítica ao afirmar que "a adoção dessa política desmantelou a proposta de ensino técnico-profissional que vinha sendo estruturada no país desde 1940" (2010, p.123).
} 
(CNE) /Câmara de Educação Básica (CEB) no 5/2011. A proposta da atual das DCNEB traz a realidade social, a formação integral do sujeito, a relevância sobre o meio ambiente e a preocupação de sobre como a Base Nacional Comum seria implantada nas escolas.

A preocupação quanto a como se dará a implementação das DCNEB pelos sistemas de ensino, bem como quanto à conscientização necessária à efetivação das referidas Diretrizes em sala de aula evidenciam a necessidade do incremento de investimentos na formação docente. No entanto, o documento propõe que a formação continuada seja motivada pela escola, respeitando as particularidades de cada uma. A não-especificação de um indicativo para instituir políticas públicas que contemplem a formação continuada dos professores, deixa um espaço vago no que tange à implementação de novas diretrizes. Essa indefinição, por um lado, sugere que a escola tem autonomia para organizar seu projeto político pedagógico, possibilitando criar projetos internos de formação continuada entre os próprios professores. Por outro lado, muitos fatores influenciam para que tais projetos não sigam adiante (a exemplo das políticas salariais, haja vista que os professores são remunerados por hora/aula). Portanto, a não-existência de uma política pública para a formação continuada de professores é um desafio a ser superado.

As DCNEB indicam que há necessidade de aproximação da lógica dos discursos normativos com a lógica social, ou seja, a dos papéis e das funções sociais em seu dinamismo. Em outros termos, as políticas públicas instituídas podem não ser simbolizadas pelos docentes a ponto de eles apropriarem-se delas. Caso não haja um projeto de qualificação para os professores, muito provavelmente as informações em que se baseiam as políticas não serviram como orientadoras das práticas docentes. $\mathrm{O}$ avanço para a educação nacional é inegável (a partir de suas propostas nas DCNEB), mas mostra-se necessário reconhecer que há um longo caminho a ser percorrido para a consolidação de uma educação na qualidade desejada. Ouvir o que pensam aqueles que fazem a educação escolar no seu dia a dia, em especial os professores, é uma estratégia que pode contribuir para a efetividade das políticas.

\section{TRAJETÓRIA METODOLÓGICA}

Com o intuito de compreender as simbolizações de docentes, o presente estudo investigou, à luz da Teoria das Representações Sociais, o que pensam os professores sobre a implantação do Decreto $n^{\circ}$ 5.154/04. Nesse sentido, a busca pelas representações que os professores que estão envolvidos no ETIM possuem sobre o ensino integrado recorreu à explicação sobre o fenômeno representacional, assim como à conceituação sobre o objeto da representação, tendo em conta que, conforme Sá, esses termos não são equivalentes. 
Os fenômenos da representação social estão "espalhados por aí", na cultura, nas instituições, nas práticas sociais, nas comunicações interpessoais e de massa e nos pensamentos individuais. Eles são, por natureza, difusos, fugidios, multifacetados, em constante movimento e presente em inúmeras instâncias de interação social. Assim, esses fenômenos simplesmente não podem ser captados pela pesquisa científica de modo direto e completo (SÁ, 1998, p.21).

O fenômeno diferencia-se do objeto em si, porque, para que um objeto se torne fenômeno para representação social, é necessário que exista interesse dos sujeitos. Conforme explicam Guareschi e Roso (2014, p. 28),

[...] nem todo fenômeno é uma representação social, a teoria das representações sociais [...] estuda e constrói teoria sobre aqueles fenômenos sociais que se tornam, por uma razão ou outra, sujeitos de interesse público. [...] fenômenos que são pensados e discutidos, [...] que causam tensão e provocam ações.

Isso posto, o estudo das representações sociais requer o desenvolvimento de técnicas adequadas à investigação do fenômeno perseguido. Em outros termos, a Teoria das Representações Sociais também propõe combinações de métodos ou "triangulações", por entender que tais procedimentos podem oferecer mais possibilidades de análise. Assim, as pesquisas em representações sociais utilizam abordagens tanto qualitativas quanto quantitativas, baseadas em diferentes métodos de coleta de dados.

Nesse sentido, o presente estudo recorreu à análise de conteúdo de dados textuais: (a) obtidos por meio da discussão por e-mail de oito professores que participavam de uma reunião pedagógica em que um dos itens da pauta era o ETIM e se propuseram a compartilhar suas percepções para além da reunião. Trata-se de uma troca de e-mails entre professores que trabalham em diferentes escolas técnicas estaduais do CEETEPS, acerca do ensino médio integrado; (b) constantes de planos de trabalho docentes de professores de uma escola técnica estadual do CEETEPS localizada na zona leste da cidade de São Paulo; (c) provenientes do texto elaborado pelo SINTEPS, denominado "O ETIM e os programas da Educação Profissional e Tecnológica. Aspectos para o debate e subsídios às reinvindicações dos trabalhadores do Centro".

A partir dessa tríplice análise ${ }^{7}$, o estudo buscou oferecer elementos que contribuam para a proposição de ações de dentro para fora da escola, e que possibilitem o desenvolvimento de um trabalho que aproxime os professores e viabilize um trabalho integrado.

\footnotetext{
${ }^{7}$ Para Maxwell (1996, p. 30), a triangulação "reduz o risco de que as conclusões de um estudo reflitam enviesamentos ou limitações próprios de um único método".
} 


\subsection{Os planos de trabalho docente}

O contexto de produção dos planos de trabalho docente ${ }^{8}$ consiste em uma escola técnica estadual do CEETEPS, situada na zona leste da cidade de São Paulo. A escola conta hoje com 12 turmas de 40 alunos no ETIM e oferece cursos técnicos nessa modalidade de ensino em dois eixos tecnológicos: (a) Controle e Processos Industriais, com os cursos de Eletrônica e Automação Industrial, e (b) Gestão e Negócios, com os cursos de Administração de Empresas e Secretariado. A escolha da escola deu-se por ser ela uma das pioneiras na implantação do ETIM.

Como instrumento de planejamento, desenvolvimento e controle das aulas, o Centro Paula Souza, seguindo as orientações das Diretrizes Curriculares Nacionais para a Educação Profissional Técnica de Nível Médio (DCNEP), desenvolveu um modelo de plano de trabalho para que todos os professores padronizem a elaboração de suas aulas. Vale dizer que a escola possui 85 professores, sendo que 43 lecionam na modalidade ETIM. Foram analisados 62 planos de trabalho dos professores de ETIM, divididos entre os que lecionam componentes da Base Nacional Comum e os que lecionam na Educação Profissional ${ }^{9}$.

\subsection{A troca de e-mails entre os docentes}

Os professores do CEETEPS, como trabalham na modalidade contratual hora/aula, frequentemente têm dificuldade para encontros presenciais, visto que seus horários de trabalho são diferentes. Durante o semestre, uma forma usual de comunicação entre os docentes é a troca de $e$-mails, utilizados para responder às diversas provocações que ocorrem no cotidiano e expressas nas reuniões pedagógicas. Acerca do ETIM, há divergências de opiniões entre os docentes e, especialmente em uma reunião pedagógica, ocorrida no dia 05 de dezembro de 2015, na Etec contexto desta pesquisa, houve um debate acerca da temática. Nele, alguns professores defenderam e outros opuseram-se a essa modalidade de ensino. Para dar oportunidade a todos de expressarem suas opiniões e não ultrapassarem o tempo da pauta do dia, foi sugerido, por parte dos docentes, que o debate continuasse por e-mail, a fim de buscar uma solução para construção de um ensino de fato integrado a partir da interdisciplinaridade.

\footnotetext{
${ }^{8}$ Vale ressaltar que os professores da Educação Profissional ministram mais de um componente curricular. Um plano de trabalho do mesmo componente curricular pode ser utilizado por todas as turmas correspondentes, por esse motivo a quantidade de PTD e de Docentes não coincide.

${ }^{9}$ Observou-se que, entre os docentes que lecionam Componentes da Base Nacional Comum, há um equilibrio entre os sexos, já na educação profissional prevalece a presença de homens. Para ambos os eixos, a faixa etária está entre 31 e 40 anos. Ao analisar o tempo de docência no CEETEPS, percebeu-se a concentração no intervalo entre 5 e 10 anos.
} 
Por serem consideraras uma fonte de livre expressão, as informações desses $e$-mails, com as devidas autorizações dos docentes, foram analisadas pela pesquisa. Os 8 professores ${ }^{10}$ envolvidos na troca de e-mails também tiveram seus planos de trabalhos analisados, pois trabalham na escola contexto da investigação, bem como em outras Etecs do CEETEPS ${ }^{11}$.

\subsection{Textos em debate do SINTEPS: “O ETIM e os programas da Educação Profissional e} Tecnológica. Aspectos para o debate e subsídios às reinvindicações dos trabalhadores"

O Conselho de Diretores de Base do SINTEPS é composto por professores e funcionários do CEETEPS. Os Diretores de Base representam o sindicato nas próprias unidades escolares e são convocados mensalmente para as reuniões. Como representantes das unidades escolares, ou das escolas da região, os Diretores de Base têm a responsabilidade de fazer a interface escola-sindicato, levando e trazendo reinvindicações e propostas de assuntos que afetam os professores e a educação, com o propósito de desenvolver pautas de discussão que contribuam para a construção de uma educação de qualidade, reconhecendo que esta somente será possível se os professores forem reconhecidos como protagonistas nas possibilidades de mudança.

Atualmente, o SINTEPS conta com 72 Diretores de Base. Destes, 42 são professores ${ }^{12}$ concursados e ativos do CEETEPS e os outros 30 são funcionários administrativos das escolas. Da escola caracterizada no item 3.1, dois docentes são Diretores de Base do SINTEPS e trabalham em mais duas escolas do CEETEPS. O texto do SINTEPS analisado foi construído coletivamente. Sua pauta foi discutida em plenária e todas as questões levantadas pelos CDBs. $\mathrm{Na}$ ocasião, as questões expressavam reivindicações do movimento sindical.

\section{AS CATEGORIAS TEMÁTICAS ENCONTRADAS}

A análise de conteúdo respeitou os procedimentos descritos por Bardin (1995) e Franco (2012), conjugadas às orientações de Bauer e Gaskell (2011). Após a leitura flutuante dos três tipos de material discursivo, foram identificadas categorias de sentido que, posteriormente, compuseram categorias temáticas mais amplas.

\footnotetext{
10 Dos oito professores participantes, sete moram na Zona Leste, cursaram pós-graduação lato sensu, são concursados e ensinam em mais de uma Etec. Um deles possui pós-graduação strictu sensu. Três são mulheres e dois são filiados ao SINTEPS. A idade varia entre 28 e 56 e o tempo de docência varia entre 4 e 25 anos.

11 Somados aos outros 35 professores da unidade escolar, que tiveram seus planos de trabalhos analisados, totalizaram 62 planos de trabalhos. Desses, 32 planos eram da Educação para Formação Geral e 30 da Educação Profissional.

12 Dos 42 professores, 25 são homens e 17, mulheres. A maioria possui de 5 a 10 anos de experiência, o que coincide com a expansão das escolas estaduais de Educação Profissional do CEETEPS.
} 
As categorias temáticas encontradas na análise de cada um dos discursos foram, em seguida, pareadas de modo a favorecer a triangulação. Nesse tocante, privilegiou-se o conteúdo em detrimento da frequência de aparição dos conteúdos, de modo a permitir que, após o processo de inferência, fosse possível identificar quatro categorias temáticas cujos conteúdos se manifestaram nos três diferentes tipos de material discursivo. São as categorias: (a) Aprendizagem dos alunos; (b) Formação integral: cultura, ciência, trabalho; (c) Interpretações acerca da satisfação do aluno com o ETIM; (d) Prática e formação docente. As referidas categorias são brevemente descritas a seguir com vistas a justificar as considerações feitas pelo estudo.

\subsection{Aprendizagem dos alunos}

A análise dos três documentos evidencia que a construção de uma representação acerca do ETIM, no que diz respeito à aprendizagem dos alunos, tem um longo caminho a percorrer para chegar próximo ao que foi proposto nas DCNEM, a saber:

Art. $5^{\circ}$. O Ensino Médio, em todas as suas formas de oferta e organização, baseia-se em:

I - formação integral do estudante;

II - trabalho e pesquisa como princípios educativos e pedagógicos, respectivamente;

III - educação em direitos humanos como princípio nacional norteador;

IV - sustentabilidade ambiental como meta universal;

V - indissociabilidade entre educação e prática social, considerando-se a historicidade dos conhecimentos e dos sujeitos do processo educativo, bem como entre teoria e prática no processo de ensino-aprendizagem;

VI - integração de conhecimentos gerais e, quando for o caso, técnicoprofissionais realizada na perspectiva da interdisciplinaridade e da contextualização;

VII - reconhecimento e aceitação da diversidade e da realidade concreta dos sujeitos do processo educativo, das formas de produção, dos processos de trabalho e das culturas a eles subjacentes;

VIII - integração entre educação e as dimensões do trabalho, da ciência, da tecnologia e da cultura como base da proposta e do desenvolvimento curricular.

$\S 1^{\circ} \mathrm{O}$ trabalho é conceituado na sua perspectiva ontológica de transformação da natureza, como realização inerente ao ser humano e como mediação no processo de produção da sua existência.

$\S 2^{\circ} \mathrm{A}$ ciência é conceituada como o conjunto de conhecimentos sistematizados, produzidos socialmente ao longo da história, na busca da compreensão e transformação da natureza e da sociedade.

$\$ 3^{\circ}$ A tecnologia é conceituada como a transformação da ciência em força produtiva ou mediação do conhecimento científico e a produção, marcada, desde sua origem, pelas relações sociais que a levaram a ser produzida.

$\S 4^{\circ} \mathrm{A}$ cultura é conceituada como o processo de produção de expressões materiais, símbolos, representações e significados que correspondem a valores 
éticos, políticos e estéticos que orientam as normas de conduta de uma sociedade.

Art. $6^{\circ} \mathrm{O}$ currículo é conceituado como a proposta de ação educativa constituída pela seleção de conhecimentos construídos pela sociedade, expressando-se por práticas escolares que se desdobram em torno de conhecimentos relevantes e pertinentes, permeadas pelas relações sociais, articulando vivências e saberes dos estudantes e contribuindo para o desenvolvimento de suas identidades e condições cognitivas e socioafetivas. (DCNEM, 2012, p.2)

Nos planos de trabalho docente, em sua totalidade, os termos dos professores relacionados à aprendizagem são palavras de ordem (dever, saber, reconhecer, dedicar, identificar, relacionar). Nesse tocante, não se encontrou indício acerca do processo de despertar o interesse do aluno. Por outro lado, nas trocas de $e$-mails, evidenciaram-se certa culpabilidade do aluno - "o aluno não tem seriedade, não consegue fazer conexões" -, bem como uma preocupação com a falta de materiais adequados e com a quantidade de matérias que o ensino integrado do CEETEPS exige do estudante. Nos documentos do SINTEPS, pode ser encontrada a preocupação com o atendimento de necessidades básicas do aluno para estimular o processo de aprendizagem, como, por exemplo, a alimentação, a locomoção e a infraestrutura institucional. Ao confrontar as informações, não foi possível identificar apropriação dos professores acerca do ensino integrado, no que concerne a essa categoria temática.

\subsection{Formação integral: cultura, ciência, trabalho}

Ao analisar os planos de trabalho docente, foi possível identificar formas de desenvolvimento da rotina de ensino-aprendizagem, apesar de não sugerirem atividades interdisciplinares. Por outro lado, a análise dos e-mails trocados, nesse tocante, novamente indica uma culpabilidade dos alunos, quando da interpretação, pelos docentes, de falta de maturidade por parte dos estudantes e da afirmação de que os alunos não seguirão na área de estudo. No que se refere ao documento do SINTEPS, esse faz a proposta tal como consta do Decreto 5.154/04, direcionada à formação integral do sujeito, no entanto, são teorias que precisam ser levadas à vida prática no chão da escola.

\subsection{Interpretações acerca da satisfação do aluno com o ETIM}

Notou-se que os planos de trabalho docente reproduzem o discurso oficial. O olhar para o aluno é sempre formal, caracterizado por exigências da vida acadêmica. Por outro lado, das trocas de e-mails, foi possível depreender que os docentes sensibilizam-se com os alunos. Eles os percebem quando dizem que o acesso à escola e a escolha de um curso integrado foram feitos 
pelos pais; entendem o cansaço dos alunos e demonstram preocupação quanto ao desenvolvimento humanístico voltado para questões políticas, críticas e cidadãs. Percebem, também, que os adolescentes e jovens brincam muito, sobretudo os alunos recém-ingressos. Para os professores, isso significa falta de maturidade. Por sua vez, o documento do SINTEPS não se dedica a propor um estudo sobre a satisfação do estudante.

\subsection{Prática e formação docente}

Da análise dos planos de trabalho docente, foi possível inferir que não consistem ferramenta efetiva de apoio às atividades, haja vista a reprodução dos mesmos textos em planos de trabalhos distintos, referentes a diferentes componentes curriculares. Nas trocas de $e$-mails, por outro lado, há indícios das dificuldades do exercício do trabalho, sobretudo quando é mencionada a necessidade de negociação entre professores. No entanto, é apenas o documento produzido pelo SINTESP que propõe o que é necessário para formação de planos de trabalho que o ensino integrado exige.

\section{UMA SÍNTESE POSSÍVEL}

Nos planos de trabalho docente, foram utilizados "chavões". Tais documentos seguem uma padronização tanto de linguagem, quanto dos procedimentos didáticos escolhidos. "Aula expositiva", "vídeo", "estudos dirigidos" aparecem em todos os planos. A proposta de recuperação é reproduzida igualmente em todos eles, "a recuperação será continuada", e nenhum plano de trabalho evidencia um projeto interdisciplinar, bem como a palavra integrado.

Por outro lado, os e-mails trocados evidenciam uma preocupação voltada para a atitude do aluno, mas não são buscadas questões que levem à reflexão sobre a própria prática docente. Frequentemente foram citadas questões acerca do cumprimento de regras e foi possível observar uma tendência à culpabilização dos estudantes quanto às questões de aprendizagem. Ambivalências também foram evidenciadas nas trocas de $e$-mails, pois, ao mesmo tempo em que os docentes se queixavam da falta de maturidade dos alunos, evidenciavam a preocupação como o bem-estar do estudante, com o tipo de conhecimento que terão e o que farão no futuro.

Por sua vez, o documento elaborado pelo SINTEPS direcionou-se para a implementação de políticas públicas que possibilitam efetivar o ensino integrado, voltado para uma formação politécnica. Nesse documento, os docentes, autores, posicionaram-se de forma mais fundamentada e focada, motivo pelo qual expressa mais elementos voltados para o cumprimento do Decreto 5.154/04. 
O que se aproxima do termo ensino integrado é o termo utilizado para a escola em tempo integral. Nesse sentido, podemos definir tempo como um período contínuo e integral. Logo, escola em tempo integral pode ser definida como aquela em que o aluno fica o dia todo na escola completando os períodos. E, para tal, necessita de uma infraestrutura completa para o atendimento dos educandos.

Diante da realidade e da falta de políticas públicas que estabeleçam critérios para o ensino integrado e a escola em tempo integral, novamente as escolas fazem o que conseguem com os recursos que dispõem, e é o que acontece nas escolas do CEETEPS, onde se utilizou do conceito de escola em tempo integral e adaptaram-se os cursos de ensino técnico integrado ao médio, porém sem a infraestrutura necessária, haja vista as escolas em tempo integral da Secretaria do Estado da Educação de São Paulo ${ }^{13}$.

\section{CONSIDERAÇÕES FINAIS}

Da triangulação das informações estudadas, foi possível depreender a impossibilidade de identificar uma representação acerca do ETIM, vez que esse não consiste em um objeto de representação para os docentes. Com base nas informações analisadas, pode-se afirmar que, contribui para tal indefinição, a carência de política pública de qualificação para os professores, bem como a falta de uma proposta institucional de formação integral para os alunos.

Em outros termos, para os professores participantes do estudo, as políticas de Estado não favorecem amplamente a execução do ensino integrado, o que colabora para criar tensões no campo educacional. Apesar de a proposta do ETIM existir há mais de uma década e afetar diretamente a prática profissional dos docentes, os professores que estão cotidianamente na escola não construíram um conhecimento acerca no ensino integrado.

A ausência de informações e a urgência das demandas da escola orientam o discurso dos docentes no sentido de culpar os alunos pelas dificuldades de aprendizagem e de criticar a quantidade de matérias que os discentes têm que estudar. Por outro lado, a falta de formação especializada, associada à deficiência das condições institucionais, faz os docentes sensibilizarem-se com suas angústias dos estudantes, que passam a ser deles também, dado o desamparo que sentem.

Nesse tocante, acredita-se que a pesquisa realizada ofereça elementos que podem colaborar para a elaboração de medidas no sentido de colocar em prática a conexão entre os

\footnotetext{
${ }^{13}$ Conforme informações disponíveis em: <http://www.educacao.sp.gov.br/escola-tempo-integral>. Acesso em:
} 12 mar. 2017. 
conteúdos, entre as metodologias de ensino e entre as ações da escola, objetivando efetivar uma educação profissional de nível médio genuinamente integrada.

\section{REFERÊNCIAS}

ALMEIDA, Júlio Gomes. Como se faz uma escola aberta: experiência de abertura de uma escola na periferia de São Paulo. São Paulo: Paulus, 2005.

ARRUDA, Ângela. Teoria das Representações Sociais e teorias de gênero, Cadernos de Pesquisa, n. 117, p. 127-147, nov. 2002. Disponível em: <http://www.scielo.br/pdf/cp/n117/ 15555.pdf>. Acesso em: 23 mar. 2016.

BARDIN, Laurence. Análise de conteúdo. Lisboa: Edições 70, 1995.

BAUER, Martin W.; GASKELL, George. Pesquisa qualitativa com texto, imagem e som: um manual prático. 9. ed. Petrópolis: Vozes, 2011.

BRASIL. Lei $n^{\circ}$ 378, de 13 de janeiro de 1937. Dá nova organização ao Ministério da Educação e Saúde Pública. Disponível em: 〈http://www2.camara.leg.br/legin/fed/lei/19301939/lei-378-13-janeiro-1937-398059-publicacaooriginal-1-pl.html >. Acesso em: 23 out. 2015.

BRASIL. Lei $n^{\circ} 4.024$ de 20 de dezembro de 1961. Fixa as diretrizes e bases da educação nacional. Lex: Legislação Federal, 1961.

BRASIL. Lei no 4.244 de 09 de abr. 1943. Lei orgânica do ensino secundário. Lex: Legislação Federal, 1942.

BRASIL. Decreto $n^{\circ} 2.208$ de 17 de abril de 1997. Regulamenta o $§ 2^{\circ}$ do art. 36 e os artigos 39 e 42 da Lei 9.394/96, que estabelece as diretrizes e bases da educação nacional e dá outras providências. Disponível em: 〈http://www.planalto.gov.br/ccivil_03/decreto/D2208.htm>. Acesso em: 10 jun. 2015.

BRASIL. Decreto $n^{\circ} 5.154$ de 23 de julho de 2004. Regulamenta o $§ 2^{\circ}$ do art.36 e os artigos 39 a 41 da Lei 9.394/96, que estabelece as diretrizes e bases da educação nacional e dá outras providências. Disponível em: 〈http://www.planalto.gov.br/ccivil_03/_Ato2004-2006/2004/ Decreto/D5154.htm \#art9>. Acesso em: 10 jun.2015.

BRASIL. Lei de Diretrizes e Bases da Educação Nacional: Lei n ${ }^{\circ}$ 9.394, de 20 de dezembro de 1996, que estabelece as diretrizes e bases da educação nacional. - 5. ed. - Brasília: Câmara dos Deputados, Coordenação Edições Câmara, 2010.

BRASIL. Atualização das Diretrizes Curriculares Nacionais para a Educação Profissional Técnica de Nível Médio aos dispositivos da Lei no 11.741/2008, Versão “Águas de Março", 2012. Disponível em: 〈http://portal.mec.gov.br/index.php?option=com_docman\& view=download\&alias=10221-consultaeaudenciapublicas-den-2012\&category slug=marco2012-pdf\&Itemid=30192 > . Acesso em: 10 jun. 2015. 
BRASIL. Resolução CNE/CEB $n^{\circ}$ 04/2005 de 27 de outubro de 2005. Inclui novo dispositivo à Resolução CNE/CEB 1/2005, que atualiza as Diretrizes Curriculares Nacionais definidas pelo Conselho Nacional de Educação para o ensino Médio e para a Educação Profissional Técnica de Nível Médio às disposições do decreto n 5.154/2004. Disponível em: <http://portal.mec.gov.br/cne/arquivos/pdf/rceb04_05.pdf>. Acesso em 10 jun. 2015

BRASIL. Ministério da Educação. Secretaria de Educação Básica. Diretrizes Curriculares Nacionais da Educação Básica. Brasília, MEC/SEB/DICEI, 2013.Disponível em: $<$ http://portal.mec.gov.br/docman/julho-2013-pdf/13677-diretrizes-educacao-basica-2013pdf/file>. Acesso em: 22 ago.2015.

BRASIL. Ministério da Educação. Secretaria de Educação Básica. Parâmetros Curriculares Nacionais: Ensino Médio. Brasília, MEC/SEB, 2000. Disponível em: <http://portal.mec.gov. br/seb/arquivos/pdf/blegais.pdf> . Acesso em: 22/08/2015.

BRASIL. Lei $n^{\circ} 11.741$ de 16 de jul. 2008. Altera dispositivos da Lei $\mathrm{n}^{\circ}$ 9.394, de 20 de dezembro de 1996. Disponível em: 〈http://www2.camara.leg.br/legin/fed/lei/2008/lei-1174116-julho-2008-578206-publicacaooriginal-101089-pl.html>. Acesso em: jun. 2015.

CEETEPS. Governo do Estado de São Paulo, Centro de Educação Tecnológica Paula Souza. Disponível em: 〈http://centropaulasouza.sp.gov.br>. Acesso em: 12 jun. 2015.

CEETEPS. Planos de Cursos. Disponível em: <http://www.etecvotuporanga.com.br/planosde-curso/>. Acesso em: 22 out. 2015.

CUNHA, Luiz Antônio. O ensino profissional na irradiação do industrialismo. São Paulo: Editora UNESP, Brasília, DF: Flacso, 2005.

FRANCO, Maria Laura P. B. Análise de Conteúdo, Brasília, 4. ed. Líber Livro, 2012.

FRIGOTTO, Gaudêncio; CIAVATTA, Maria; RAMOS, Marise (Orgs.). Ensino médio integrado: concepções e contradições. 3.ed. São Paulo: Cortez, 2012.

GUARESCHI, Pedrinho; ROSO, Adriane. Teoria das representações sociais - sua história e seu potencial crítico e transformador. E. M. Q. O. Chamon, P. A. Guareschi, \& P. H. F. Campos. (Orgs). Textos e debates em representação social. Porto Alegre: ABRAPSO. 2014, p. $17-40$.

JOVCHELOVITCH, Sandra. Os contextos dos saberes: representações, comunidade e cultura. 2 ed. Petrópolis, RJ: Vozes, 2011.

MARX, Karl; ENGELS, Frédéric. Textos sobre educação e ensino. Campinas, SP: Navegando, 2011.

MAXWELL, Joseph A. Qualitative research design: an interactive approach. Thousand Oaks: Sage, 1996.

MOSCOVICI, Serge. A Psicanálise, sua imagem e seu público. Tradução de Sonia Fuhrmann. Petrópolis: Vozes, 2012. 
MOSCOVICI, Serge. Psicologia das minorias ativas. Tradução do Grupo de Leituras Ideologia, Comunicação e Representações Sociais; responsável Pedrinho A. Guareschi. Petrópolis, RJ: Vozes, 2011.

NOVAES, Adelina; SOUSA, Clarilza Prado. Protagonismo? - Representações e identidade sociais de estudantes de pedagogia sobre o Brasil. In: ARRUDA, Ângela; SOUSA, Clarilza Prado de. (Org.). Imaginário e representação social de universitários sobre o Brasil e a escola brasileira: um estudo construído com múltiplas possibilidades. São Paulo: Annablume, 2013.

PEREIRA, Evas Waisros; TEIXEIRA, Zuleide Araújo. A Educação básica redimensionada. In: BRZEZINSKI, Iria (Org.). LDB interpretada: diversos olhares se entrecruzam. São Paulo: Cortez, 1997.

REGATTIERI, Marilda e CASTRO, Jane Margareth. Ensino médio e educação profissional: desafios da integração. $2^{\circ}$ ed., Brasília: UNESCO, 2010.

SÁ, Celso P. A construção do objeto de pesquisa em representações sociais. Rio de Janeiro: EdUERJ, 1998.

SÃO PAULO. Secretaria Geral Complementar: Departamento de Documentação e Informação. Decreto Lei $n^{\circ}$ 0/1969, de 06 de outubro de 1969, cria o Centro Estadual de Educação Tecnológica de São Paulo e dá providências correlatas: Disponível em: <http://www.al.sp.gov.br/norma/?id=72563 $>$. Acesso em: 15 set.2015.

SÃO PAULO. Secretaria Geral Complementar: Departamento de Documentação e Informação. Decreto Lei $n^{\circ} 37.735$ de 27 de outubro de 1993. Autoriza a transferência das Escolas Técnicas Estaduais para o Centro Paula Souza. Disponível em: http://www.al.sp.gov.br/repositorio/legislacao/decreto/1993/decreto-37735-27.10.1993.html>. Acesso em 15 set. 2016.

SÃO PAULO. Secretaria do Estado da Educação: SEE-SP. Disponível em: <http://www.educacao.sp.gov.br/a2sitebox/arquivos/documentos/342.pdf >. Acesso em: 13 maio. 2016.

SINTEPS, Sindicato dos Trabalhadores do Centro Paula Souza. O ETIM e os programas atuais da Educação Profissional e Tecnológica: aspectos para o debate e subsídios às reinvindicações dos trabalhadores do Centro: Disponível em: <http://www.SINTEPS.org.br/ index.php/campanha-contra-o-fim-do-em-nas-etecs/>. Acesso em: $17 \mathrm{fev} .2016$.

SEIDMANN, Susana; THOMÉ, Sandra: DI IORIO, Jorgelina; AZZOLLINI, Susana. Construção identitária e prática docente: reflexões a partir da Teoria das Representações Sociais. In: PLACCO, Vera Maria N. Souza; VILLAS BÔAS, Lúcia P. Santiso; SOUSA, Clarilza P. (Org.). Representações sociais: diálogos com a educação. Curitiba: Champagnat; PUC-PR, 2012, p. 43-56.

TARDIF, Maurice. Saberes docentes e formação profissional. 14. ed. Petrópolis, RJ: Vozes, 2012. 


\section{SOBRE AS AUTORAS}

Adriana Cristina Ruescas Santana é Mestre em Educação pela Universidade Cidade de São Paulo (UNICID) e professora do ensino técnico no Centro Estadual de Educação Tecnológica Paula Souza (CEETEPS)

E-mail: ruescas@ig.com.br

Adelina de Oliveira Novaes é pesquisadora do Departamento de Pesquisas Educacionais da Fundação Carlos Chagas, onde atua na coordenação do Centro Internacional de Estudos em Representações Sociais e Subjetividade - Educação, como pesquisadora permanente da Cátedra UNESCO sobre Profissionalização Docente e como membro do conselho científico da Cátedra Franco-Brasileira Serge Moscovici. Docente/pesquisadora do Programa de Mestrado Acadêmico em Educação e do Mestrado Profissional Formação de Gestores Educacionais da Universidade Cidade de São Paulo (UNICID). E-mail: anovaes@fcc.org.br 